\title{
Transition from School to University Mathematics: Manifestations of Unresolved Commognitive Conflict in First Year Students' Examination Scripts
}

\author{
Athina $\operatorname{Thoma}^{1}$ (D) Elena Nardi ${ }^{1}$
}

Published online: 29 November 2017

(C) The Author(s) 2017. This article is an open access publication

\begin{abstract}
We explore the transition from school to university through a commognitive (Sfard 2008) analysis of twenty-two students' examination scripts from the end of year examination of a first year, year-long module on Sets, Numbers, Proofs and Probability in a UK mathematics department. Our analysis of the scripts relies on a preliminary analysis of the tasks and the lecturers' (also exam setters') assessment practices, and focuses on manifestations of unresolved commognitive conflict in students' engagement with the tasks. Here we note four such manifestations concerning the students' identification of and consistent work with: the appropriate numerical context of the examination tasks; the visual mediators and the rules of school algebra and Set Theory discourses; the visual mediators of the Probability and Set Theory discourses; and, with the visual mediators and rules of the Probability Theory discourse. Our analysis suggests that, despite lecturers' attempts to assist students towards a smooth transition to the different discourses of university mathematics, students' errors at the final examination reveal unresolved commognitive conflicts. A pedagogical implication of our analysis is that a more explicit and systematic presentation of the distinctive differences between these discourses, along with facilitation of the flexible moves between them, is needed.
\end{abstract}

Résumé Nous investigons la transition de l'école vers université à l'aide d'une analyse commognitive (Sfard 2008) des copies de vingt-deux étudiants provenant d'examens finaux d'un module d'enseignement sur « Ensembles, Nombres, Preuves, Probabilités », qui s'étend sur toute la première année d'un programme d'étude britannique de

Athina Thoma

a.thoma@uea.ac.uk

Elena Nardi

e.nardi@uea.ac.uk

1 School of Education and Lifelong Learning, University of East Anglia, Norwich Research Park, Norwich NR4 7TJ, UK 
mathématiques. Notre analyse des copies prend en compte nos analyses commognitives préablables des tâches et des pratiques d'évaluation des enseignants (qui sont aussi les auteurs des tâches d'évaluation), et nous nous focalisons sur les manifestations de conflits commognitifs non résolus dans les efforts des étudiants pour résoudre les tâches. Ici, nous notons quatre telles manifestations qui concernent l'identification et la consistance de leur travail dans: le contexte numérique approprié; les médiateurs visuels et les règles du discours de l'Algèbre et de la Théorie des Ensembles; les médiateurs visuels du discours de la Théorie des Probabilités et la Théorie des Ensembles; et les médiateurs visuels et les règles du discours des probabilités. Notre analyse suggère que, en dépit des efforts des enseignants à assister les étudiants dans leur transition vers les discours différents des mathématiques universitaires, les erreurs commises par les étudiants montrent des conflits commognitifs non résolus. Une implication pédagogique de notre analyse est la nécessité d'une présentation plus explicite et systématique des différences caractéristiques entre ces discours, en unisson avec un effort pour faciliter le passage flexible entre eux.

Keywords Students' scripts · Examination tasks · Commognitive conflict · Transition

Mots-clés Ècrits d'elève · Copies d'examen · Conflit commognitif·Transition·Évaluation

\section{Introduction}

The first year of university mathematics, and especially students' transition from school to university mathematics, has been the focus of much research in mathematics education (Gueudet 2008). The content of the first-year examination papers is seen as highlighting what lecturers consider important (Smith et al. 1996; Van de Watering et al. 2008) and students' ways of approaching those examination tasks can demonstrate how the students experience this transition and where their enculturating difficulties may lie. Researchers have studied assessment tasks using different theoretical frameworks and focusing on different aspects of the tasks (Bergqvist 2007; Darlington 2014; Maciejewski and Merchant 2016; Tallman et al. 2016). Some researchers also propose characterisations of examination tasks (Tallman et al. 2016) or examine what mathematical reasoning lecturers prioritise when they design tasks (Bergqvist 2012).

In our study, we use Sfard's (2008) theory of commognition to characterise students' engagement with university mathematics discourses in the context of the closed-book examinations of a first-year mathematics module (course unit) in a well-regarded UK mathematics department. Previously (Thoma and Nardi 2016), we analysed samples of examination tasks and lecturer interview data to gain insight into the mathematical discourse the students are expected to engage with when solving the tasks and to highlight lecturers' intended assessment practices. In this paper, we further these analyses by examining the students' actual engagement with mathematical discourses as evident in the examination scripts. More specifically, we aim to investigate students' scripts for underlying, unresolved commognitive conflicts between the school and university mathematics discourses. To this aim, we illustrate four different manifestations of commognitive conflict, observed in the students' scripts.

In what follows, we review literature related to university mathematics examination tasks and associated lecturer perspectives as well as to the transition between school 
and university. Then, we present the basic tenets of commognitive theory with a focus on those parts of the theory that are pertinent to the analysis of the data in this paper. Next, we present evidence from our data, the students' examination scripts, which manifests instances of commognitive conflict observed in the students' responses. Finally, we conclude with an overview of the different manifestations of commognitive conflict evident in our data, and a discussion of possible implications for lecturers' practices. We also consider the potentialities of the commognitive framework as a tool for analysing this type of data.

\section{Examination Tasks and Lecturer Perspectives}

Examination tasks have been the focus of several studies, particularly in the area of Calculus (e.g. Bergqvist 2007; Tallman et al. 2016). Focusing on students' degree of familiarity with the tasks, Bergqvist (2007) classifies tasks depending on whether the task requires imitative or creative reasoning, a distinction coined by Lithner (2008). In doing so, Bergqvist takes into account the context of the module. She finds that the majority of the tasks require imitative reasoning, namely memorized (e.g. tasks involving a proof or a definition which the students were informed that it might be included in the exams (Bergqvist 2007, p. 358)) and algorithmic reasoning (e.g. a task which requires the derivative of a function, the algorithm for which occurred three or more times in the textbook (p. 362). These results agree with Tallman et al. (2016) who analysed 150 Calculus examination papers in order to identify the skills and understandings that the tasks require of the students. Their analysis, using an adaptation of Bloom's taxonomy (1956) by Anderson et al. (2001), suggests that the tasks mostly require students to remember theory and recall and apply a procedure; and, that explanation is not often required of the students.

Using the MATH taxonomy (Smith et al. 1996), an adaptation of Bloom's taxonomy (1956), Darlington (2014) considers the mark distribution of the examination tasks from first year undergraduate modules with topics in Algebra and Real Analysis. The MATH taxonomy has the following groups of knowledge and skills: Group A (Factual Knowledge and Fact Systems), Group B (Information Transfer, Application to New Situations) and Group C (Justification and Interpretation, Implications, Conjectures and Comparisons, Evaluation). Her analysis shows that the majority of the marks were allocated to tasks requiring justifications, interpretations, implications, conjectures and comparisons (Group C). Taking into account the findings from the previous studies on Calculus examinations tasks, Darlington (2014) also suggests that these requirements vary in accordance with the topic examined.

All aforementioned studies focus on examinations from first year modules. An analysis of tasks from different modules across the four years of an undergraduate mathematics degree is offered by Maciejewski and Merchant (2016). They analyse the tasks using Bloom's taxonomy (1956) aiming to find the relationship between study approaches and module grades in undergraduate mathematics modules in all four years of the undergraduate mathematics course. Their results show that first year modules focus on calculations and procedures, with more emphasis given to evaluation and creativity towards the later years of the course, where many tasks also require recalling and understanding theorems and definitions. 
Lecturers' views on examination tasks were examined by Bergqvist (2012) and Tallman et al. (2016). Through interviewing lecturers, Bergqvist (2012) found that, in constructing the examination tasks, they take into account: the proficiency and prior knowledge of each particular student cohort; course content; degree of difficulty; whether students have encountered a task before or not; and, departmental and disciplinary tradition. Tallman et al. (2016), using a questionnaire, examined lecturers' intended and implemented practices regarding their choice of focus for examination tasks (e.g. on a concept or a procedure), and whether the tasks ask students to provide explanation for their answers. The analysis of the lecturers' questionnaire responses shows a contrast with the findings of the analysis of the tasks by the researchers. Specifically, in their questionnaire responses, the lecturers claim that they usually require students to justify and explain their thinking; and, they also intend to achieve a balance between tasks focusing on demonstrating the understanding of mathematical concepts and tasks focusing on procedures. However, the task analysis by the researchers questions these claims and indicates a difference between lecturers' intended and implemented assessment practices.

We note that in Tallman et al. (2016) the lecturers were asked to reflect on examination tasks in general. Our work aligns more with Bergqvist's (2012) approach as we ask the lecturers to reflect upon specific examination tasks. For example, in Thoma and Nardi (2016) we offer an analysis of the examination tasks, of a first year module, and the corresponding lecturers' interview data in which we discern their intended assessment practices. We return to this analysis later in the paper. However, we note that our analysis suggests that lecturers' intended assessment practices are informed by their experiences as to where the students might face difficulties and take into account that the students are transitioning from school to university mathematics.

Our previous analysis suggests that lecturers aim to assist students in the transition from school to university mathematics. In the context of examination tasks, this can be seen through their choices regarding the structure and requirements from each part of the task. In this paper, we turn to the students' examination scripts in order to explore whether the lecturers' choices generate the desired results. We do so after a brief outline of the commognitive theoretical constructs that are instrumental in our analysis of the student scripts. In this outline, we also include a note on the distinct differences, particularly in the UK context where the study is conducted, between school and university mathematics discourses. A brief outline of our study's context, aims and methods follows right after.

\section{A Commognitive Take on the Discourses of School and University Mathematics}

The theory of commognition has become a widely used discursive approach in mathematics education (Tabach and Nachlieli 2016) and is also now used more and more in studies at university level (Nardi et al. 2014). In this theory, discourses are defined as "different types of communication, set apart by their objects, the kinds of mediators used, and the rules followed by participants and thus defining different communities of communicating actors" (Sfard 2008, p. 93). Mathematics is seen as a discourse with specific characteristics: word use (e.g. integers, functions), visual 
mediators (e.g. graphs of functions), narratives (e.g. definitions, propositions) and routines (e.g. proving, defining). Sfard offers a categorisation of the routines in: deeds (changing objects, p. 237), rituals ("creating and sustaining a bond with other people", p. 241) and explorations (producing or substantiating an endorsed narrative, p. 224). She classifies explorations further in: construction, substantiation and recall routines. In the commognitive framework, learning is seen as the development of the learner's discourse at object-level (developing the existing discourse) and at meta-level ("change in the metarules of the discourse" (p. 300)). Meta-level learning can be horizontal ("combining separate discourses into a single discourse by subsuming them to a new discourse" (Tabach and Nachlieli 2016, p. 302) or vertical ("combining the existing discourse with its own meta discourse", ibid.).

Mathematical discourses at university level are typically different from those at school level. We note that these differences between school and university discourses vary in different educational contexts. Sfard (2008) comments on these differences as follows: "there are important differences between construction and substantiation routines practised in colloquial and literary mathematical discourses, and these routines change again in the transition from school discourse to the scholarly discourse of mathematicians." (p. 225). She also highlights characteristics of the university mathematical discourse: "first, this discourse's extreme objectification; secondly, its reliance on rules of endorsement that privilege analytic thinking and leave little space for empirical evidence; and thirdly, the unprecedented level of rigour that is to be attained by following a set of well-defined formal rules." (Sfard 2014, p. 200). Upon arrival at university, students are expected to shift their discourse into that of university mathematics. As they work towards achieving this discursive shift, students may experience commognitive conflicts, namely "the encounter[s] between interlocutors who use the same mathematical signifiers (words or written symbols) in different ways or perform the same mathematical tasks according to differing rules" (Sfard 2008, p. 161). In our study, we examine manifestations of commognitive conflict stemming from the use of visual mediators and rules from the school mathematics discourse in examination tasks at university level and we find that these commognitive conflicts remain unresolved.

The differences between school and university mathematical discourses have been the focus of several researchers who deploy the commognitive framework. Investigating the transition between secondary and university studies in mathematics, Stadler (2011) studies the mathematical discourse used by undergraduate students while solving a task with the help of their lecturer. Her commognitive analysis highlights the presence of two different mathematical discourses, the school mathematics discourse, which the students draw from, and the scientific mathematics discourse used by the expert interlocutor, the lecturer. This difference between students' and lecturers' discourses is also emphasized by Güçler (2013). Her analysis emphasizes that the students face difficulties when the shifts in the lecturer's discourse are not made explicit. The focus of the above studies is the difference between school and university mathematics discourses. However, commognitive conflicts can also occur within the discourses of different university mathematics modules. For example, Ioannou $(2012,2016)$ reports commognitive conflicts the students experience within the discourse of Group Theory. In our study, we examine students' scripts for manifestations of commognitive conflict occurring when school and university mathematical discourses or discourses of different university mathematics modules conflict. Conflicts of this ilk were noted by 
the lecturers participating in an earlier study by Nardi (1999) as school-university, intra(within the same university module), inter- (between different university modules) conflicts. The interviewed lecturers deemed these conflicts as highly impactful on students' enculturation into the discourse of university mathematics - and they recognized the importance of being explicit about these. However, Nardi (1999) noted that "very little substantive teaching practice" (p. 50) was found in the accounts of the interviewees, with regard to how students can be assisted towards the resolution of these conflicts.

Certain distinct differences between the school and university mathematics discourses are noticeable in the UK educational context (Nardi 2008, p. 93-101) where the students participating in our study have been mostly educated. One such difference is that, in the UK school mathematics discourse, students are not asked to engage with substantiation routines (such as proving). Another difference - to which we return more elaborately in the data analysis section of our paper - is that students are not expected to engage with the routine of identifying the domain of a variable (for example, in the context of studying functions) as, implicitly, the expectation is that the numerical context of such problems is always the real numbers. In the university mathematics discourse, the numerical context may change from one module to another, and even from one part of a task to another. Notably, one of the metarules of the university discourse is the identification of the numerical context used in that task and the careful examination of each of the narratives belonging to that numerical context. The data and analysis we present in this paper examine these and other differences between university and school mathematics discourses in the context of commognitive conflicts manifested in the students' responses to Year 1 examination tasks. We now outline briefly the context, aims and methods of our study before delving into the presentation and analysis of our data.

\section{Context, Aims and Methods of the Study: Examination Tasks and Students' Scripts}

The data we sample from in this paper are part of a dataset collected for the doctoral study of the first author which aims to characterise assessment discourses at university level, using a commognitive analytical framework. The module, Sets, Numbers and Probability, which this paper focuses on, is offered during the first year. The Sets, Numbers and Proofs part is taught in the autumn semester covering: sets (notations, operations, cardinality and countability), functions (basics, injection, surjection), proof (direct proof, by induction, examples and counterexamples, by contradiction), number theory (greatest common divisors, prime numbers, modular arithmetic) and equivalence relations. The probability part of the module is taught in the spring semester, covering: classical definition (defining the probability $P(A)$ as the quotient of the number of ways that event $A$ can happen during an experiment over the total possible outcomes of an experiment), Kolmogorov's axioms, propositions (e.g. $P(\varnothing)=$ 0 , If $A, B$ are disjoint events then $P(A \cup B)=P(A)+P(B)$ ), conditional probability, binomial and Bayes' theorem, independent events, discrete distributions (binomial, geometric and Poisson) and continuous distributions (uniform, Gaussian, exponential).

In this paper, we focus on students' scripts from the final examination of the module. The examination had two compulsory and four optional tasks. Each part of the module had one compulsory and two optional tasks. The students were asked to solve five tasks, both of the compulsory and three of the optional, during two hours. Each task corresponded to twenty 
marks and the pass grade of the examination was forty marks. Fifty-four students participated in the final examination of the module. The first author selected twenty-two of those scripts, representing a variety of marks (Thoma and Nardi in press, Fig. 3 on p. 4). These scripts were then analysed for instances where the students' errors may be the result of unresolved commognitive conflict. Focusing on the use of words, visual mediators and meta-discursive rules, we examined the scripts for instances where this use indicated conflating discourses. After the initial identification of these instances, we coded the scripts according to the discourses that were being used in each particular instance. Commognitive analysis of the tasks also assisted in the identification of the different discourses that students were expected to navigate across in each of the tasks. The coded instances form the four different manifestations of commognitive conflict we analyse in this paper.

In what follows, we first introduce the parts of the examination tasks that correspond to the students' scripts reported here - for a detailed analysis of the compulsory tasks see Thoma and Nardi (2016). We then present the four manifestations of commognitive conflict that emerged from our analysis with excerpts from the students' scripts. We note that these excerpts are scanned images, which occasionally include lecturers' hand-written comments, as the students' scripts were scanned after the lecturers had marked them. Where the lecturer wrote something on the script that can be confused with the student's own writing, we alert the reader accordingly in the caption of the scanned figure. Table 1 includes a summary of the tasks, with the main mathematical content that the task focused on, the number of students that engaged with the task and the average, maximum and minimum marks that the students achieved in each of the tasks.

Table 1 Summary of the tasks from the closed-book examination

\begin{tabular}{|c|c|c|c|c|c|}
\hline \multirow[t]{2}{*}{ Task } & \multirow[t]{2}{*}{ Mathematical content } & \multirow{2}{*}{$\begin{array}{l}\text { Number } \\
\text { of students }\end{array}$} & \multicolumn{3}{|c|}{ Students' marks } \\
\hline & & & Average & Maximum & Minimum \\
\hline 1 - Compulsory & $\begin{array}{l}\text { Proof by induction, } \\
\text { Greatest common divisors, } \\
\text { Proof by contradiction }\end{array}$ & 54 & 16.85 & 20 & 4 \\
\hline 2 - Compulsory & $\begin{array}{l}\text { Kolmogorov's axioms, Propositions, } \\
\text { Conditional probability }\end{array}$ & 54 & 14.17 & 20 & 5 \\
\hline 3 - Optional & $\begin{array}{l}\text { Operations on Sets, } \\
\text { Equivalence relations }\end{array}$ & 53 & 13.23 & 20 & 0 \\
\hline 4 - Optional & $\begin{array}{l}\text { Injective and Surjective functions, } \\
\text { Modular arithmetic }\end{array}$ & 54 & 14.31 & 20 & 0 \\
\hline 5 - Optional & $\begin{array}{l}\text { Continuous random variable, } \\
\text { Expectation and Variance, } \\
\text { Probability density function, } \\
\text { Cumulative distribution function }\end{array}$ & 46 & 9.98 & 20 & 0 \\
\hline 6 - Optional & $\begin{array}{l}\text { Discrete random variable, } \\
\text { Probability density function, } \\
\text { Expectation }\end{array}$ & 12 & 6 & 14 & 0 \\
\hline
\end{tabular}




\section{Four Manifestations of Commognitive Conflict}

Our analysis of students' scripts highlighted four different manifestations of commognitive conflict concerning: the numerical context of the task; the visual mediators and the rules of the discourse on school algebra and Set Theory; the visual mediators of the discourse on Probability and Set Theory; the visual mediators and rules of the discourse on Probability. The first two manifestations concern the transition from a discourse that the students are familiar with from secondary school (e.g. school algebra) to a university mathematics discourse (e.g. Set Theory). The other two concern transitions across discourses within university mathematics (e.g. Set Theory and Probability). In each of the four sections that follow, we first present the part of the task which corresponds to the sampled students' writing. We then provide an overview of the twenty-two students' performance in this task and we discuss related excerpts from the students' scripts which illustrate what we see as evidence of unresolved commognitive conflict.

\section{Working within the Numerical Contexts of Number Theory and Real Analysis}

In part (ii) of task 1 (Fig. 1) and part (i) of task 4 (Fig. 2), the students are asked to engage with different numerical sets. In commognitive terms, this request implies engagement with different discourses: the discourse of integers and the discourse of real numbers. We analysed the students' responses to these parts of the tasks and we found that there were errors, which occurred because the students did not constrain the narrative that they produced within a specific numerical context. We call this manifestation of the underlying commognitive conflict as "working within the appropriate numerical context". In the case of our examples, this work refers to the numerical contexts of a Number Theory task (integers) and Real Analysis (real numbers). The student responses, which follow, illustrate a difficulty to frame their narrative within a specific numerical context. The ten students' scripts that illustrate this difficulty, stemming from what we see as a hitherto unresolved commognitive conflict, correspond to different parts of the tasks from the Numbers, Sets and Proofs part of the module. This manifestation is evident in students' responses to the compulsory task (Fig. 1), more specifically to parts 1(iia) and 1(iic). All students attempted part 1(iia), which is worth four marks. However, four received no or one mark for their responses. Twenty-one students responded to 1(iic) and seven of them received zero marks out of two. We note that we provide the information on marks to put the tasks in context (and, for example, indicate what parts of the task the lecturers valued more). This does not mean that the errors stemming from the commognitive conflicts reported here are the only reason for

(a) Suppose $a, b, d, m, n$ are integers. Give the definition of what is meant by saying that $d$ is a divisor of $a$. Using this, prove that if $d$ is a divisor of $a$ and $d$ is a divisor of $b$, then $d$ is a divisor of $m a+n b$.

(b) Use the Euclidean algorithm to find the greatest common divisor $d$ of 123 and 45 . Hence (or otherwise) find integers $m, n$ with $123 m+45 n=d$.

(c) Do there exist integers $s, t$ such that $123 s+45 t=7$ ? Explain your answer carefully.

Fig. 1 Task 1(ii) - Compulsory task in Sets, Numbers and Proofs 
Suppose $A$ and $B$ are sets and $f: A \rightarrow B$ is a function. Define what is meant by $f$ being surjective and what is meant by $f$ being injective.

For each of the following functions decide whether it is injective, surjective (or both, or neither). Give brief definitions for your answers.

(a) $g: \mathbb{R} \rightarrow \mathbb{R}$ where $g(x)=1 /\left(1+\sin ^{2}(x)\right)$ for $x \in \mathbb{R}$.

(b) $h: \mathbb{Z} \rightarrow \mathbb{Z}$ where $h(n)=3 n$ for $n \in \mathbb{Z}$.

Fig. 2 Task 4i - Optional task in Sets, Numbers and Proofs

the loss of marks. We present the manifestation of this commognitive conflict regarding parts 1(iia) and 1(iic) (Fig. 1) in more detail in Thoma and Nardi (in press).

In this task, the students are asked to work within the set of integers. The set of integers is closed under addition, subtraction and multiplication. However, it is not closed under division. The fractions $\frac{d}{a}$ and $\frac{d}{b}$ that appear in student [03]'s response (Fig. 3) have an integer as a numerator and an integer as a denominator. If the student had written the fraction the other way around, then the result would have been an integer. However, in the way that the fraction is written, the result is a non-integer (apart from when $d$ is equal to $a$ ), as $d$ is the divisor of $a$ and $d$ is smaller or equal to $a$ by definition. Thus, the variables introduced by the student as $m$ and $n$ are non-integers. This is conflicting with the introduction of the variables $m$ and $n$ in the task as integers. The word use in the script is also suggestive of unresolved commognitive conflict. The student uses the terms

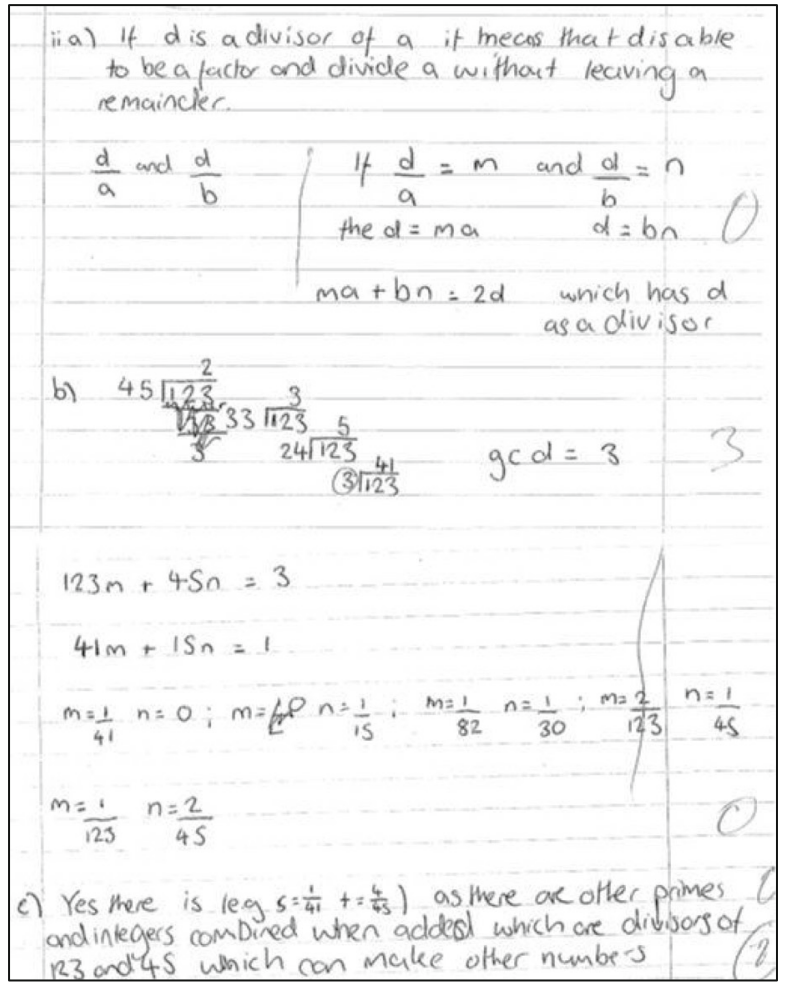

Fig. 3 Student [03]'s response to 1(ii) 
"primes" and "integers" to talk about fractions $\frac{1}{41}$ and $\frac{4}{45}$ calculated in the previous part of the task. All these instances in the writing illustrate that the student's work is not retained within the numerical context (integers) in which this task is to be carried out. The lecturer, to assist students, formulates the task so that the students are first asked for the definition (to allude to the students the discursive objects that they are dealing with). He then gradually builds the task connecting all parts and stressing that all variables mentioned in this task are integers.

In the school mathematics discourse, the students are not used to questioning which number set a numerical result belongs to. The student assumes that the set of numbers introduced last in school is the one that they should be working with. However, within university mathematics discourses, the context of the task can be different in each case. The variables used, the numerical values that the variables take and the operations that are appropriate in each case depend on the context of the module / mathematical topic the task is set in. In this example, the student is using the variables as they are introduced by the lecturer in the task without questioning the numerical context. We see this lack of questioning as ritualised use of $s$ and $t$, the visual mediators of the variables in the task.

This manifestation of commognitive conflict is also visible in students' scripts corresponding to part 4(ib) of the task, where the students are asked to substantiate whether the given function is injective and surjective (Fig. 2). Twenty-one students responded to 4(ib), worth four marks, and six of them received no or one mark for their response.

In part 4(ib) of the task, student [08] produced a narrative about the function from the integers to the integers containing a graph (Fig. 4). However, the graph is presented as a straight line without questioning the fact that this function is discrete and not

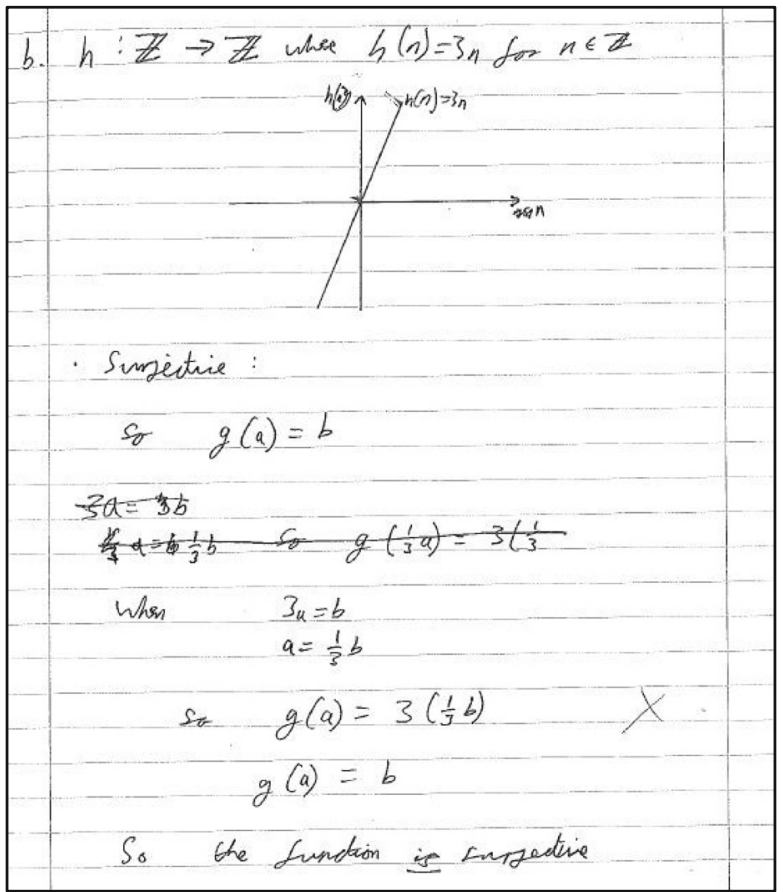

Fig. 4 Student [08]'s response to 4(ib). The lecturer added the cross symbol at the right-hand side of the image 
continuous. The graph here suggests that student [08] did not consider that this is a graph of a function that has integers as a domain and codomain. This is also visible in the writing that accompanies the graph. The student introduces two variables $a$ and $b$ without defining their numerical context.

In trying to identify whether the function is surjective, the student tries to find $a$ writing $3 a=b$ and dividing both sides of the equality by 3 . This operation would be appropriate and it would not change the nature of the numbers on each side of the equality if the numbers belonged to the real numbers. However, in this case, the numerical values of the variables should be integers, not real numbers. If we assume that the student intended to define $b$ as belonging to the integers, in trying to find $a, \mathrm{~s} / \mathrm{he}$ did not take into account that dividing an integer $b$ by 3 does not necessarily mean that the result would also be an integer. We see these errors as possibly due to the difference between school and university mathematics discourses. In the former, students are not expected to engage with specifying the number set which a given variable should take its values. Since the latest numerical context introduced is the real numbers and the set of real numbers is closed under division, the division by 3 on both sides of the equality indeed shows that $3 a=b$ can always be solved for $a$ in the case of real variables. However, with integer variables $a$ and $b, b / 3$ is not always an integer.

\section{Discourses on Set Theory and Algebra: Visual Mediators and Rules}

This manifestation of commognitive conflict is visible in seven students' responses to task 3(i) part 1 (Fig. 5), where students were asked to substantiate the equality between two sets. The commognitive conflict that we observed analysing these responses occurs between the Set Theory and the school algebra discourses. The students use rules from the algebra discourse, not the Set Theory discourse, to prove the equality.

Student [08]'s response (Fig. 6) illustrates this conflation of rules of the school algebra and Set Theory discourses. The student realises the rule of the Set Theory discourse for substantiation of the equality, namely that both sides of the equality must be examined. S/he starts from the left-hand side, where the union of the two sets becomes addition of the two sets, and says that this implies the right-hand side. Similarly, for the other side of the equality, the student's writing illustrates conflation of the rules governing the two discourses: s/he uses factorisation to show that the right-hand side of the equality equals the left-hand side. The writing also illustrates conflating union $(U)$ in Set Theory and addition $(+)$ in algebra. The student uses rules from Set Theory (examines both sides of the equality) as well as from algebra (addition instead of the union, factorisation). This conflation is not seen as appropriate by the lecturer and the response receives zero marks.

Student [15]'s response (Fig. 7) manifests a similar commognitive conflict and receives zero marks for this part of the task. The student rewrites the equality to be proven, starts from the right-hand side to try to substantiate the given equality. As we can see in the rubbed out second line in the image, the student tries first to start from the left-hand side but then gives up and crosses out this attempt. Then, starting from the

(i) Prove carefully that if $A, B$ and $C$ are sets then $A \cap(B \cup C)=(A \cap B) \cup(A \cap C)$. Give an example of sets $A, B$ and $C$ such that $A \cap(B \cup C) \neq(A \cap B) \cup C$.

Fig. 5 Task 3(i) - Optional task in Sets, Numbers and Proofs 


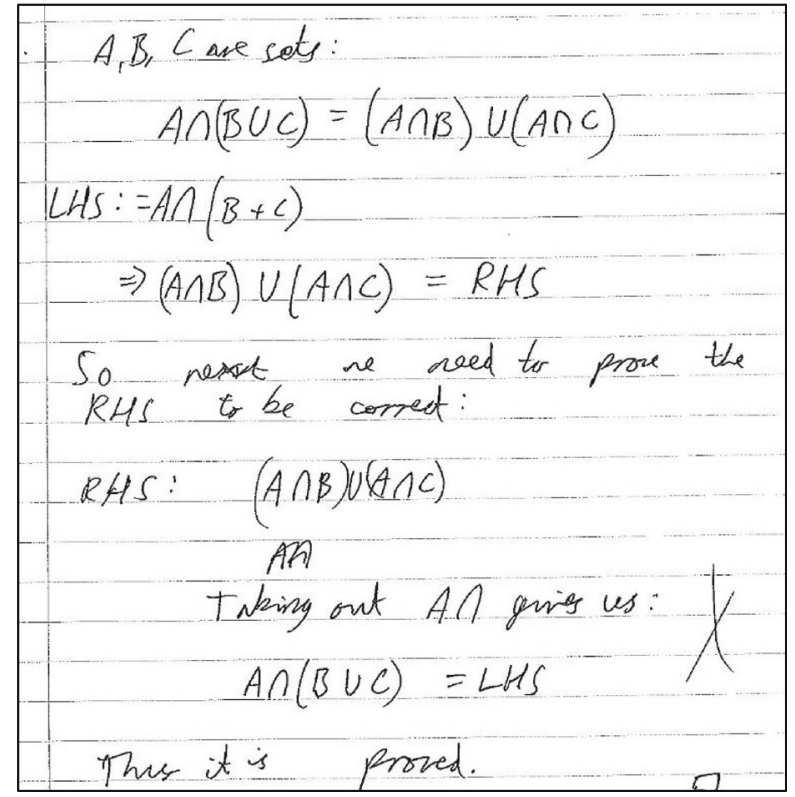

Fig. 6 Student [08]'s response to 3(i). LHS means "left-hand side", RHS means "right-hand side". The lecturer added the cross symbol

right-hand side, the student appears to interpret Set Theory signifiers as signifying "addition" (+) and "subtraction" (-) between sets. The student seems to resort here to an identity used in Probability, $P(D \cup E)=P(D)+P(E)-P(D \cap E)$. Maybe, the student, seeing the signifiers for intersection and union of sets, recalled, and deployed, the identity from the Probability discourse. We note that this example resonates also with those we cite in the following section.

A further manifestation of this conflation of the school algebra and Set Theory discourses is visible in Fig. 8. Student [06] (Fig. 8) starts by taking an element in the first set and showing that this element belongs to the second set. The student then concludes, not that the first set is a subset of the second, but that the two sets are equal. The student seems to have used algebra rules, applicable when investigating the equality of two algebraic expressions, to show the equality of two sets. Specifically, this ritual from the algebra discourse involves starting from the left or the right-hand side of the equality and then trying to prove the other part of the equality by manipulating and rearranging the first one. However, in the Set Theory discourse establishing that two sets are equal often involves two steps, the demonstration of one set being a subset of the other, and vice versa.

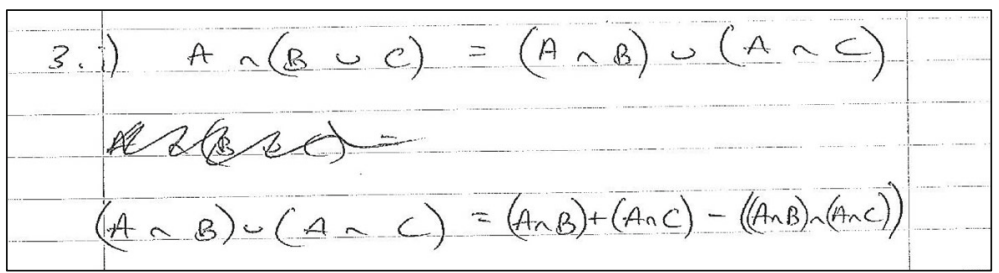

Fig. 7 Student [15]'s response to 3(i) 


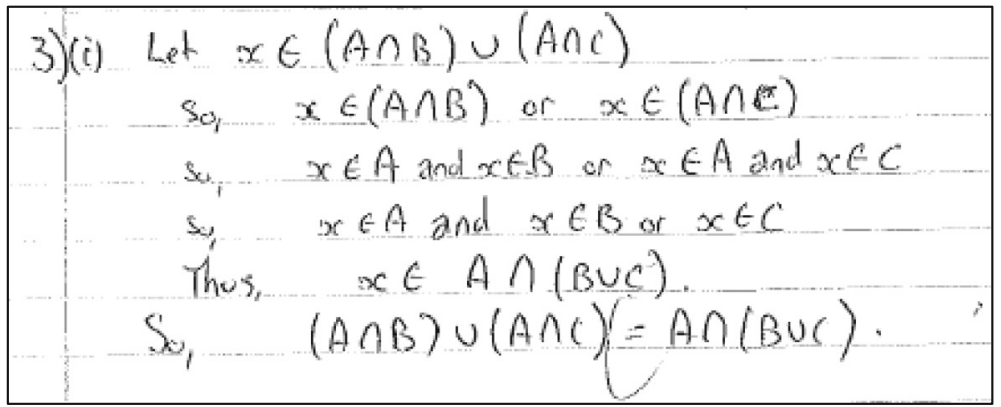

Fig. 8 Student [06]'s response to 3(i). The lecturer circled the equality sign in the last line of the student's response

\section{Discourses on Set Theory and Probability: Visual Mediators}

A manifestation of commognitive conflict, which concerns engaging with the Set Theory and Probability discourses, is visible in six students' responses to task 2(i) (Fig. 9). For a commognitive analysis of this task and lecturers' assessment practices see Thoma and Nardi (2016). The responses that we discuss in what follows correspond to students' errors using the visual mediators in ways that suggest conflation of the different discursive objects of sets and probabilities.

All twenty-two students attempted this part of the task, which was worth twelve marks out of twenty. In the first part of 2(i), the students were asked to recall Kolmogorov's axioms. The majority of the students achieved high marks in this part. However, for 2(ia) and 2(ib), where the students were asked to prove two propositions from Probability, seven students achieved zero marks for 2(ia) and eight students achieved zero marks for 2(ib).

This manifestation of commognitive conflict has to do with narratives where the distinction between the Set Theory and Probability discourses do not seem clear in the students' scripts. Specifically, the students' narratives (equalities) illustrate connections between two different mathematical objects. For example, student [01] (Fig. 10) is attempting to substantiate that the probability of event $A$ is less than the probability of event $B$, when $A$ is a subset of $B$. The student starts by defining $A$ as a subset of $B$ and then writes that " $A$ must be the probability of something within the probability of $B$ ". This illustrates confusion between event $A$, which is a subset of the sample space, and the probability $P(A)$ of event $A$, which is a value between 0 and 1 . The student provides an example as proof of this relationship between the probabilities of events $A$ and $B$.

(i) In the framework of the modern probability, give the definition of two disjoint events and state the three Kolmogorov's axioms; then use them to demonstrate the following two propositions:

(a) For any event $A=\emptyset$, prove that $P(A)=0$.

You may assume Proposition 2, that is $P\left(A_{1} \cup A_{2}\right)=P\left(A_{1}\right)+P\left(A_{2}\right)$ if $A_{1}$ and $A_{2}$ are disjoint events.

(b) For any events $A$ and $B$ such that $A \subseteq \mathrm{B}$, prove that $P(A) \leq P(\mathrm{~B})$.

Fig. 9 Task 2(i) - Compulsory task in Probability 


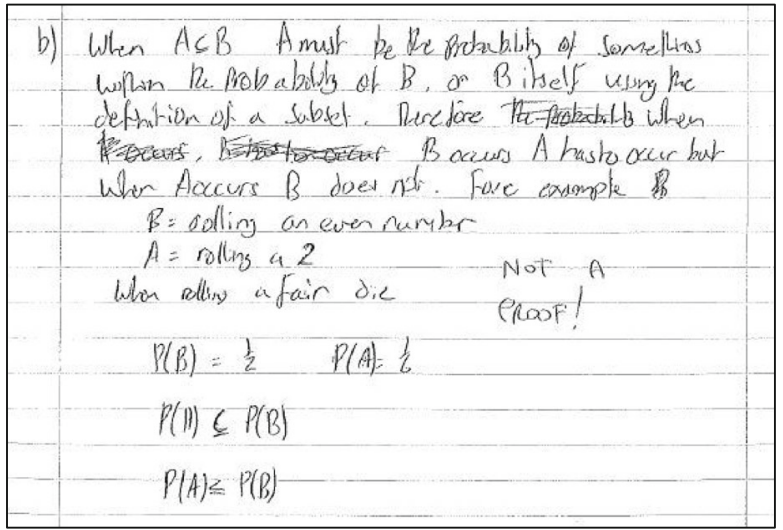

Fig. 10 Student [01]'s response to 2(ib). The lecturer wrote Not a proof!

Incidentally, we note that this illustrates commognitive conflict as to what constitutes an acceptable proof in the context of a university mathematics examination: providing an example does not actually prove that this relationship between the two probabilities stands. However, our focus here is on a different type of an unresolved commognitive conflict evident in the last two lines in the student's narrative. The first line shows the two probabilities with the visual mediator signalling that the probability of $A$ is a subset of the probability of $B$. Then the next line arrives at the desired narrative, the inequality between probabilities. Here, the writing suggests a conflation of Set Theory and Probability discourses. The discursive object of probability is a number and thus the relationship between two probabilities should be described using the mathematical signifier of inequality, whereas events $A$ and $B$ are sets and the relationship between

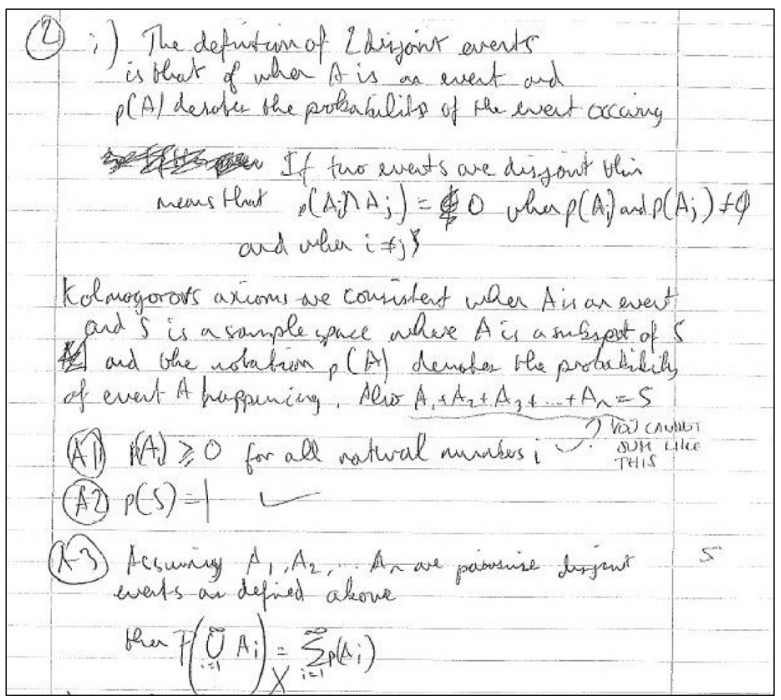

Fig. 11 Student [02]'s response to 2(i) - the third Kolmogorov's axiom is completed by the lecturer who added the probability in the left-hand side of the equality and the sum from $i=1$ to infinity in the right hand side of the equality. Also, the lecturer underlined the summation, wrote You cannot sum like this and added the check symbols 


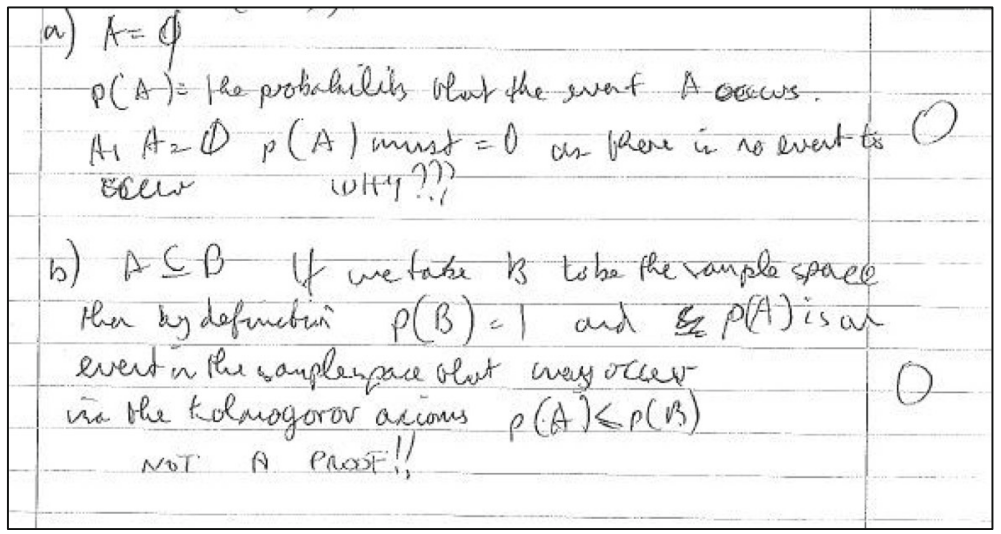

Fig. 12 Student [02]'s response to 2(i) continued - The lecturer has written the phrases why??? and Not a proof!!

them should be described using the mathematical signifier of subset. The student uses the signifier of subset at the start to illustrate the relationship between the two events and then uses it again to illustrate the relationship between probabilities. The student received one mark for this part of the task, most probably as the example provided illustrates the key element of the proposition.

Another example illustrating a similar commognitive conflict between the Set theory and Probability discourses can be seen in student [02]'s response to 2(i) (Fig. 11) where we note, in four places, conflation of the discursive objects of probabilities and events. The instances in this response where this conflation can be observed are as follows.

First, in the definition of disjoint sets, the probability of the intersection of the events is considered and the student comments that the two events must have probabilities different from the empty set, instead of having the probabilities being different from zero. In the lines that follow this, the student sets the scene for the presentation of Kolmogorov's axioms and tries to connect the sample space with the events. We observe that the events being "added" (countable events) are equal to the sample space $\mathrm{S}$. This illustrates the aforementioned conflation of probability (a number) and an event as well as conflation of numerical operations with the set-theoretical operations of union, intersection and complement. Then, for the third of Kolmogorov's axioms, the student writes that the union of the pairwise disjoint events $A_{i}$ from 0 until infinity is equal to the probability of $P\left(A_{i}\right)$. In the script (Fig. 11), the marker added the symbol of

(i) Let $X$ be a Poisson random variable with parameter $\lambda$ having probability mass function $P(X=x)=\frac{\lambda^{k} e^{-\lambda}}{k !}$

(a) Show that

$$
\sum_{k=0}^{\infty} P(X=x)=1
$$

(b) By assuming the validity of the relation in (a), calculate $E(X)$.

Fig. 13 Task 5(i) - Optional task in Probability 
(i) Define expectation $E(X)$ and variance $V(X)$ of a continuous random variable $X$.

Fig. 14 Task 6(i) - Optional task in Probability

probability in the left-hand side of the equality and the sum from $i=1$ to infinity in the right-hand side of the equality. Finally, in the student's response to 2(ib), we observe that the student writes that the probability $P(A)$ is an event in the sample space "that may occur via the Kolmogorov's axioms" (Fig. 12). Until that point in the narrative, the student was referring to events with word use that is in full resonance with Probability discourse. But then, again, the probability of an event is conflated with the event itself.

\section{Discourse on Probability: Visual Mediators}

The final example of commognitive conflict we exemplify in this paper occurs in students' engagement with the Probability discourse. More specifically, during the lectures, the students were first introduced to basic Probability and then to discrete and continuous distributions. One of the examination tasks is on a discrete distribution (Task 5(i), Fig. 13) where the variable is a "Poisson random variable" and the probability mass function is given and the other one is on a "continuous random variable" (Task 6(i), Fig. 14).

Four student scripts illustrated a conflation of the discursive objects of discrete and continuous variables, regardless of the prompts used by the lecturer in the wording of the examination task. The students' use of visual mediators, illustrates a confusion regarding the countable and continuous probability space on which the discrete and continuous random variables are defined. This manifestation of commognitive conflict is intra-discursive as it occurs during engagement with one discourse (Probability).

These two optional tasks were the ones attempted by the smallest number of students. From the twenty-two students, seventeen attempted 5(i) and only seven out of these achieved a non-zero mark. Furthermore, only seven students attempted task 6(i) and only four of them achieved a non-zero mark. We are not claiming that the only reason that the students lost marks is this manifestation of commognitive conflict. It seems though that at least four did.

In Fig. 15, student [04] attempted to solve task 5(i) which deals with a Poisson random variable. The student has re-produced the wording of the task and, in attempting to show that the sum of the probabilities is equal to 1 , added an integral. The visual mediator of the integral sign just before the probability mass function

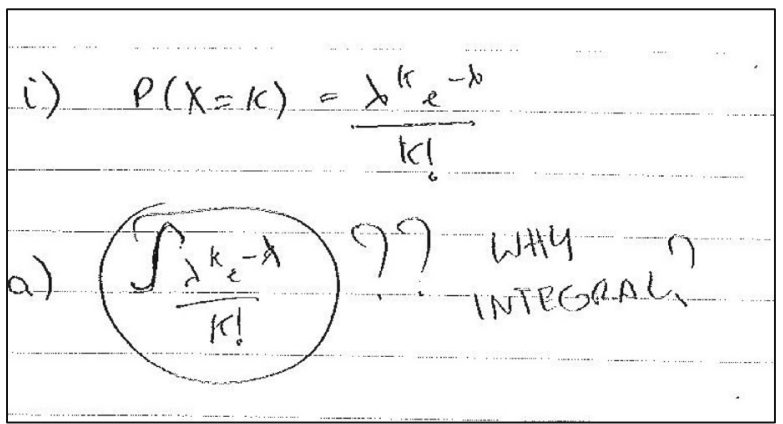

Fig. 15 Student [04]'s response to 5(i). The lecturer has circled the integral and wrote ??Why integral? 


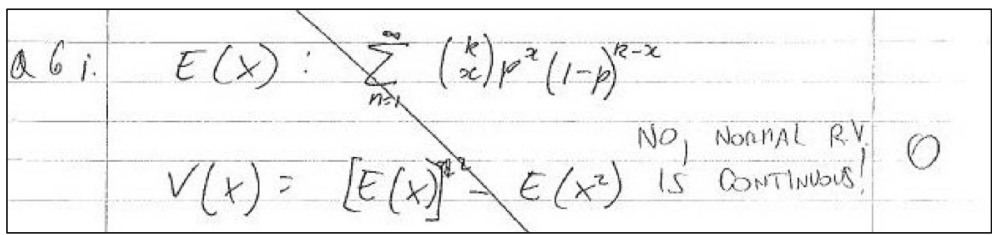

Fig. 16 Student [08]'s response to 6(i). The lecturer has crossed out the writing and wrote No, Normal R.V.(Random Variable) is continuous!

illustrates that the student conflates the discourse on discrete random variables and the discourse on continuous random variables. The student received zero marks for 5(i).

The responses from three students to task 6(i) (Fig. 14) also illustrate what we see as unresolved commognitive conflict. We should note here that the task itself starts with the statement that $X$ is a "continuous random variable". However, many students who attempted this part of the task conflated continuous random variable with discrete random variable (Fig. 16). These responses received zero marks. In Fig. 16, the student starts by writing the visual mediator of the expected value and, beside it, something like the cumulative distribution function for the binomial distribution, instead of $\int_{-\infty}^{+\infty} x f(x) d x$. We see this as illustrating a conflation of continuous and discrete random variables. For the variance, instead of providing the definition for continuous distribution, student [08]'s writing of the equality attempts connecting the expectation and the variance (true for both continuous and discrete distributions). However, in this attempt, the student does not write the expected value of $X^{2}$ minus the expected value of $X$ squared but the other way around.

This commognitive conflict is occurring within the Probability discourse and is evident in students' word use and mathematical signifiers (the written symbols) regarding discrete random variables and continuous random variables.

\section{Inter, Intra and School-University Commognitive Conflict}

The aim of the study we draw on in this paper is to examine students' engagement with the mathematical discourse in the context of closed-book examinations. Analysing students' responses to examination tasks may, in general, be an important way to increase our understanding of students' experience as they arrive from school and navigate across different university mathematics discourses. Here we have illustrated manifestations of unresolved commognitive conflict in four different cases.

In the first, difficulty with identifying and working consistently within the appropriate numerical context of the task is visible in the responses of ten out of the twentytwo students. At school level, explicit attention on the numerical context of a task is rarely given, whereas at university students are expected to engage with variables belonging to different numerical domains in different mathematical areas.

The second manifestation regards narratives from Set Theory. Seven scripts illustrate that, in the context of a Set Theory task, the students use the rules and the visual mediators from the algebra discourse instead to illustrate relationships between settheoretical discursive objects. Specifically, the scripts show that, when engaging with a 
substantiation task in the Set Theory discourse, the students use the rules for substantiating an equality within algebra. We see the first two cases of commognitive conflict as germane to the shift from the school to university mathematics discourse resonating also with what Tabach and Nachlieli (2016) see as "horizontal meta-level learning" (p.302) - see quote earlier in the paper.

This explicit distinction between the two discourses is also critical for narratives from the Probability discourse which form the third case of manifestation of commognitive conflict. The six students' scripts show conflation of objects of the Set Theory and Probability discourses. This is evident in their use of visual mediators (symbols). We see this manifestation of commognitive conflict also as an occurrence of "horizontal meta-level learning" (ibid.).

Finally, the last manifestation of commognitive conflict we exemplify in this paper regards the use of visual mediators from the Probability discourse and was observed in four students' scripts. We see this conflict as an occurrence of "vertical meta-level learning" (ibid.), as it concerns the routine of identifying which of the given variables are continuous and which are discrete.

The four manifestations of commognitive conflict we sample in this paper highlight the importance of the use of suitable visual mediators and rules in the production of narratives corresponding to a specific discourse. Recognising the discourse used and producing a narrative that can be endorsed using the rules of that discourse is a challenge in the university context. At university, students are typically expected to alternate between the many discourses of the mathematical topics they study and to adapt to the discursive context of each task. This is far less the case in the school mathematics discourse which, at least in the UK where our study is conducted, is typically the discourse of elementary arithmetic or algebra. Our examples illustrate the challenge that the students face in keeping the notation and the rules consistently within the discourse of the mathematical domain of a specific task.

Our commognitive analysis of students' responses has afforded us the capacity to identify not only the unresolved commognitive conflicts but also to comment on the different discourses and the meta-level (either "vertical" or "horizontal") learning during which these conflicts can occur. We agree with Tabach and Nachlieli (2016) that commognition is able "to highlight details of mathematical discourses (taken broadly) that have significant explanatory value" (p. 429). In resonance with previous findings (Nardi 1999) on schooluniversity, the inter-university and the intra-university course conflicts, our commognitive analysis highlights the complexity of the mathematical scripts given by the students and allows us nuanced commentary on the different discourses that the students engage in and on their moves - less or more successful - across these discourses.

We claim that such analysis of the examination tasks, students' scripts and lecturers' assessment practices offers insight into students' transitions - from school to university as well as across the different discourses of university mathematics. Our results suggest that, despite lecturers' attempts in the wording of the tasks to assist students towards a smooth alternation between these different discourses, students still experience commognitive conflicts at the final examination. The analysis in Thoma and Nardi (2016) highlights lecturers' assessment routines, some of which aim at assisting students in their engagement with mathematical discourse. Specifically, this analysis suggested that the lecturers are designing tasks with some awareness regarding the potential errors that the students may be prone to. We see these errors as a repercussion 
of the unresolved commognitive conflicts we sample here. The lecturers have observed this proneness during the year through the coursework or through marking students' examination responses in previous years. Some researchers (e.g. Güçler 2013) have suggested that students are likelier to experience these commognitive conflicts when the lecturer is not making the need for shifting from one discourse to another sufficiently explicit. Zooming into lecturers' practices about addressing or averting said commognitive conflicts during teaching or when providing students with feedback on coursework is what our analyses of the lecturer interview data is now turning towards.

Open Access This article is distributed under the terms of the Creative Commons Attribution 4.0 International License (http://creativecommons.org/licenses/by/4.0/), which permits unrestricted use, distribution, and reproduction in any medium, provided you give appropriate credit to the original author(s) and the source, provide a link to the Creative Commons license, and indicate if changes were made.

\section{References}

Anderson, L. W., Krathwohl, D. R., Airasian, P. W., Cruikshank, K. A., Mayer, R. E., Pintrich, P. R., Raths, J., \& Wittrock, M. C. (2001). A taxonomy for learning, teaching, and assessing: A revision of Bloom's taxonomy of educational objectives, abridged edition. White Plains: Longman.

Bergqvist, E. (2007). Types of reasoning required in university exams in mathematics. The Journal of Mathematical Behavior, 26(4), 348-370.

Bergqvist, E. (2012). University mathematics teachers' views on the required reasoning in calculus exams. The Montana Mathematics Enthusiast, 9(3), 371-408.

Bloom, B. S., Englehart, M. D., Furst, E. J., Hill, W. H., \& Krathwohl, D. R. (1956). Taxonomy of educational objectives: The classification of educational goals. Handbook 1: Cognitive domain. New York City: Longman.

Darlington, E. (2014). Contrasts in mathematical challenges in A-level mathematics and further mathematics, and undergraduate mathematics examinations. Teaching Mathematics and its Applications, 33(4), 213-229.

Güçler, B. (2013). Examining the discourse on the limit concept in a beginning-level calculus classroom. Educational Studies in Mathematics, 82, 439-453.

Gueudet, G. (2008). Investigating the secondary-tertiary transition. Educational Studies in Mathematics, 67(3), 237-254.

Ioannou, M. (2012). Conceptual and learning issues regarding undergraduate students' first encounter with group theory: A commognitive analysis (Unpublished $\mathrm{PhD}$ thesis). University of East Anglia.

Ioannou, M. (2016). A commognitive analysis of mathematics undergraduates' responses to a commutativity verification group theory task. In E. Nardi, C. Winsløw, \& T. Hausberger (Eds.), Proceedings of the first conference of the international network for didactic research in university mathematics (pp. 306-315). France: University of Montpellier and INDRUM.

Lithner, J. (2008). A research framework for creative and imitative reasoning. Educational Studies in Mathematics, 67(3), 255-276.

Maciejewski, W., \& Merchant, S. (2016). Mathematical tasks, study approaches, and course grades in undergraduate mathematics: A year-by-year analysis. International Journal of Mathematical Education in Science and Technology, 47(3), 373-387.

Nardi, E. (1999). The challenge of teaching first-year undergraduate mathematics: Tutors' reflections on the formal mathematical enculturation of their students. Nordic Studies in Mathematics Education, 7(2), 29-53.

Nardi, E. (2008). Amongst mathematicians: Teaching and learning mathematics at university level. New York: Springer.

Nardi, E., Ryve, A., Stadler, E., \& Viirman, O. (2014). Commognitive analyses of the learning and teaching of mathematics at university level: The case of discursive shifts in the study of calculus. Research in Mathematics Education, 16(2), 182-198. 
Sfard, A. (2008). Thinking as communicating: Human development, development of discourses, and mathematizing. New York: Cambridge University Press.

Sfard, A. (2014). University mathematics as a discourse-why, how, and what for? Research in Mathematics Education, 16(2), 199-203.

Smith, G., Wood, L., Coupland, M., Stephenson, B., Crawford, K., \& Ball, G. (1996). Constructing mathematical examinations to assess a range of knowledge and skills. International Journal of Mathematical Education in Science and Technology, 27(1), 65-77.

Stadler, E. (2011). The same but different-Novice university students solve a textbook exercise. In M. Pytlak, T. Rowland, \& E. Swoboda (Eds.), Proceedings of the seventh congress of the European society for research in mathematics education (pp. 2083-2092). Poland: University of Rzeszów and ERME.

Tabach, M., \& Nachlieli, T. (2016). Communicational perspectives on learning and teaching mathematics: Prologue. Educational Studies in Mathematics, 91(3), 299-306.

Tallman, M. A., Carlson, M. P., Bressoud, D. M., \& Pearson, M. (2016). A characterization of calculus I final exams in US colleges and universities. International Journal of Research in Undergraduate Mathematics Education, 2(1), 105-133.

Thoma, A., \& Nardi, E. (2016). A commognitive analysis of closed-book examination tasks and lecturers' perspectives. In E. Nardi, C. Winsløw, \& T. Hausberger (Eds.), Proceedings of the first conference of the international network for didactic research in university mathematics (pp. 306-315). France: University of Montpellier and INDRUM.

Thoma, A., \& Nardi, E. (in press). Discursive shifts from school to university mathematics and lecturer assessment practices: Commognitive conflicts regarding variables. Submitted to CERME10 (10 ${ }^{\text {th }}$ Conference of European Research in Mathematics Education).

Van de Watering, G., Gijbels, D., Dochy, F., \& Van der Rijt, J. (2008). Students' assessment preferences, perceptions of assessment and their relationships to study results. Higher Education, 56, 645-658. 